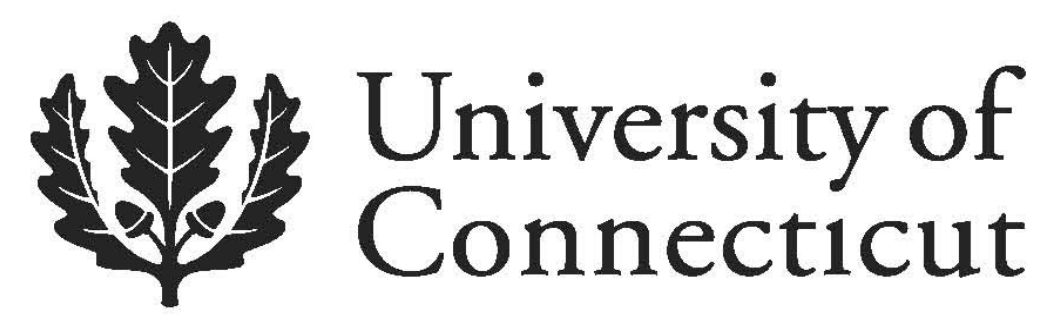

Department of Economics Working Paper Series

\title{
Demographic Transition and Economic Welfare: The Role of Humanitarian Aid
}

\author{
Stephen M. Miller \\ University of Nevada, Las Vegas \\ University of Connecticut \\ Kyriakos C. Neanidis \\ University of Manchester
}

Working Paper 2012-06

February 2012

341 Mansfield Road, Unit 1063

Storrs, CT 06269-1063

Phone: (860) 486-3022

Fax: (860) 486-4463

http://www.econ.uconn.edu/

This working paper is indexed on RePEc, http://repec.org/ 


\title{
Demographic Transition and Economic Welfare: The Role of Humanitarian Aid
}

\author{
Stephen M. Miller* \\ College of Business \\ University of Nevada, Las Vegas \\ 4505 Maryland Parkway \\ Las Vegas, Nevada, USA 89154-6005 \\ stephen.miller@unlv.edu \\ Kyriakos C. Neanidis \\ Economics \\ Centre for Growth and Business Cycle Research \\ University of Manchester \\ Oxford Road, Manchester M13 9PL \\ United Kingdom \\ kyriakos.neanidis@manchester.ac.uk
}

\begin{abstract}
This paper considers the effects of humanitarian aid on economic welfare through a demographic transition channel. We develop a two-period overlapping generations model where reproductive agents face a non-zero probability of death in childhood. As adults, agents allocate their time to work, leisure, and child rearing activities. Health status in adulthood exhibits "state dependence," as it depends on health in childhood. In this framework, we examine the effects of changes in inkind and monetary humanitarian aid on economic welfare. We conclude that if parents strongly value children, giving monetary aid produces more children and yields higher welfare. This positive welfare effect dominates an indirect negative welfare effect due to a lower growth rate. But, if parents value the quality of their children (health status), they achieve greater utility by inkind aid, which also lowers fertility and augments economic growth.
\end{abstract}

Keywords: aid; fertility; health; growth; welfare

JEL classification: C23; F35; F43; I12; O41

* Corresponding author 


\section{Introduction}

A large theoretical and empirical literature exists concerned with the effects of foreign aid on the recipient country's economic outcomes. The vast majority of these studies examine how such aid affects economic growth. Fewer studies consider welfare effects. The current study jointly explores the growth and welfare implications of one component of foreign aid, humanitarian aid. ${ }^{1}$ It tackles this issue in a model with endogenous fertility so that considerations that relate to demographic transition are also explored.

The evaluation of the effectiveness of aid on economic growth generally focuses on the various channels through which aid can influence growth: physical capital, human resources, and factor productivity. ${ }^{2}$ This literature initially examined the effectiveness of aggregate aid, whereas, more recently, researchers considered the effectiveness of its different components. The first group of empirical studies suggests that finding a significant effect of total aid on economic growth proves highly elusive, unless the analysis incorporates some country-specific preconditions. The most influential of these preconditions include the timing of aid distribution (Collier and Hoeffler 2004), climate (Daalgard et al. 2004), donor policies (Daalgard 2008), and the role of local elites (Angeles and Neanidis 2009). The second group of studies explores the effects of different aid modalities on economic growth. These various components include financial program aid, project aid, technical assistance, and humanitarian aid. Clemens et al. (2004) provide one of the first studies in this area, followed by Neanidis and Varvarigos (2009) and Minoiu and Reddy (2010), among others.

\footnotetext{
${ }^{1}$ Clemens et al., (2004) calculate that humanitarian aid represents about 10 percent of total aid flows for the period 1974 to 2001. Neanidis and Varvarigos (2009) report a similar percentage for a longer period, 1973 to 2007.

${ }^{2}$ Daalgard and Hansen (2010) provide a detailed discussion of how aid can effect economic growth through the production process.
} 
Studies that investigate the effect of economic aid on welfare also divide into two strands. First, numerous papers within the international trade theory literature determine the conditions under which aid leads to donor-enrichment and recipient-immiserization. This Transfer Paradox emerges through deterioration in aid recipient's international terms of trade. Early contributions on this subject include Bhagwati (1958), Bhagwati, et al. (1985), Lahiri and Raimondos-Møller (1995), and more recently Hatzipanayotou and Michael (2000), Lahiri et al. (2002), and Shimomura (2007). Second, other papers, within development economics, examine the welfare effects of aid transfers to the recipient country only. The typical transmission mechanisms of aid include savings and investment, human capital accumulation, and absorptive capacities (see, for example, Chatterjee, et al. 2003 and Chatterjee and Turnovsky 2005). ${ }^{3}$

This literature pays no attention to the role of fertility as a potential channel through which foreign aid can affect economic growth and welfare. A long-standing view, however, exists among development theorists that fertility considerations play a pivotal role on the longterm transition from economic stagnation to growth. The underlying mechanism corresponds to the quantity-quality trade-off for children, established by Becker (1960) and utilized by Galor and Weil (2000), Chakraborty (2004), and Agénor (2009). In this view, parents value both the number of their children and their education (or health), and given that both childrearing and education (health) involve costs, a trade-off emerges. As a result, changes in certain factors, such as a decline in mortality, an increase in wages, or technological progress, raise the rate of return on human capital, thereby inducing parents to substitute child quality for child quantity. This outcome leads to lower fertility and higher growth through human capital accumulation, thus offering a link between demographic and economic transitions.

\footnotetext{
${ }^{3}$ A few studies incorporate important elements from both strands of the literature, that is, both international termsof-trade effects and savings and investment effects (Djajić, et al. 1999, Agénor and Yilmaz 2012, and Djajić 2009).
} 
Two contributions in the literature relate economic growth outcomes to fertility decisions, where humanitarian aid influences fertility. Azarnert (2008) and Neanidis (2012) both consider the effects of foreign aid on the parents' optimization problem with respect to the choice on the quality versus quantity of children. The main point of departure between the two studies is that Azarnert (2008) introduces only monetary humanitarian aid whereas Neanidis (2012) incorporates both monetary and in-kind humanitarian aid. As a result, the predictions of these studies differ as to the effect of humanitarian aid on fertility and growth. Azarnert (2008) finds a high-fertility, low-growth equilibrium, while Neanidis (2012) discovers a more complex picture, where the effect of humanitarian aid does not take a clear sign. This ambiguity emerges because of the conflicting influences of in-kind and monetary aid on both fertility and growth. When the effect of monetary aid exceeds that of in-kind aid, then the result conforms to that of Azarnert (2008).

This paper extends the work by Neanidis (2012) to determine the effects of humanitarian aid on the economic welfare of the recipient country. Doing so illustrates the multi-faceted effect of humanitarian aid on welfare, ignored in previous studies. For example, Chatterjee, et al. (2003) and Chatterjee and Turnovsky (2005) show that a permanent increase in humanitarian (pure) aid transfers does not affect economic growth in the long run, while it raises welfare, since consumption increases by an amount equivalent to the transfer. Endogenizing fertility decisions, however, demonstrates that humanitarian aid does not always improve welfare. In our analysis, both in-kind and monetary humanitarian aid affect welfare, with the sign of the effect depending on the parents’ preferences toward child quantity (or quality). Specifically, in-kind aid leads to higher welfare, along with lower fertility and higher growth, only if parents value the quality of their children. If instead, they strongly value the number of children, in-kind aid diminishes 
welfare. But in this case, monetary aid yields higher welfare, which coexists with higher fertility and lower growth.

The paper proceeds as follows. Section 2 presents the model. Section 3 solves the model for the equilibrium outcomes of the endogenous variables and derives the expressions for economic growth and welfare. It then determines the effects of changes in in-kind and monetary humanitarian aid on economic growth and welfare. Section 4 concludes and describes the implications of our findings for the design of aid transfer programs.

\section{Model $^{4}$}

Consider a small overlapping generations (OLG) economy, where activity extends over an infinite discrete time period. The economy produces one homogeneous good, which is consumed only in that period, with labor as the single input. Individuals in each generation live (at most) for two periods: childhood and adulthood. Each individual receives one unit of time in childhood and two units in adulthood. Children depend on their parents for consumption and healthcare. Adults supply one unit of labor inelastically at a given wage rate, which finances consumption in adulthood and raises children. Adult agents also receive a permanent flow of humanitarian aid from external donors.

Each adult becomes a parent and bears $n$ children, each of which possess the same innate abilities and the same initial health status. The cost of keeping children healthy, however, involves both the parent's time and spending on marketed goods (food, medicines, etc.). Adults determine the allocation of their non-work unit of time between childrearing and leisure. ${ }^{5}$

\footnotetext{
${ }^{4}$ This section relies on the model developed in Neanidis (2012).

${ }^{5}$ The distinction of the adults' time between a unit of work and a non-work unit devoted to childrearing and leisure is not decisive for our findings. The results carry through if one assumes instead that adult time is divided across the three activities. As it will become clear, this reflects the influence of childrearing time on labor productivity.
} 
At birth, children face a non-zero probability of dying, which decreases in the amount of in-kind (food and medical) aid consumed. The health status of children depends not only on parents' income, but also on the time parents spend in childrearing and on their health status (see Powdthavee and Vignoles, 2008, for health status). Adult health status, in turn, depends linearly on the health status as a child, indicating 'state dependence' in health outcomes (Case et al., 2005). Finally, all markets clear and no debts or bequests occur between generations.

\section{Foreign Aid}

Altruistic donors give foreign aid in two forms: monetary and in-kind. ${ }^{6}$ Using either type of aid, donors want to improve the nutritional levels of children, the most vulnerable group of the population. As a result, each household receives financial aid, $A^{c}$, proportional to the number of children, $n_{\mathrm{t}+1}$, so that, total monetary aid equals $A^{c} n_{\mathrm{t}+1} \cdot{ }^{7}$ We measure monetary aid in units of labor income, a necessary assumption to sustain an ongoing growth equilibrium. Thus, we define monetary aid per child as follows:

$$
A^{c}=c \alpha_{t+1} w_{t+1}, c \in(0,1)
$$

where $c$ represents monetary financial aid as a fraction of the recipient's labor income, $\alpha_{t+1}$ is individual labor productivity, and $w_{t+1}$ denotes the real wage rate.

In addition to monetary aid, each child receives in-kind aid in the form of food and medicines, $A^{f}$. Also expressing the monetary value of in-kind aid in units of labor income yields:

$$
A^{f}=f \alpha_{t+1} w_{t+1}, f \in(0,1),
$$

with $f$ measuring the generosity of the foreign donors with respect to in-kind aid. A series of studies show that this type of aid plays a vital role in saving children's lives by limiting

\footnotetext{
${ }^{6}$ The donors solely determine the amount of aid, making this exogenous to the recipients.

${ }^{7}$ In other words, each child receives this type of aid to increase its likelihood of survival. That is, aid goes to all children, whether they subsequently survive or not.
} 
nutritional distress and minimizing the risk of death associated with diseases such as measles and diarrhea (e.g., Huff and Jimenez, 2003; De Waal, et al., 2006; Center for Global Development, 2007; Plumber and Neumayer, 2009; and Neanidis, 2012). This evidence supports the notion that in-kind aid increases the likelihood $\left(p_{t}\right)$ of a child's survival to adulthood. We, thus, model the probability of survival as depending on the fraction of income allocated to in-kind aid as follows: $p_{t}(f)$ with $p_{t}^{\prime}(f)>0$ and $p_{t} \in(0,1){ }^{8}$

\section{Households}

Let $N_{t}$ equal the number of adults in period $t$, with each adult bearing $n_{t}$ children. As described above, the probability that a child survives to adulthood equals $p_{t}(f) \in(0,1)$. For tractability, the number of surviving children equals the expected number of survivors. To avoid convergence of population to zero, we assume that $p_{t} n_{t} \geq 1$. Raising a child involves two costs, spending $\varepsilon_{t+1} \in$ $(0,1)$ units of time on each child's health care, which implies the allocation of $\varepsilon_{t+1} n_{t+1}$ units of time, and spending a fraction $\theta \in(0,1)$ of adult income on each child's health, which implies foregone wage income and consumption.

Let $y_{t+1}$ denote the individual's income in $t+1$. Thus, the total cost of raising $n_{\mathrm{t}+1}$ children, if all survive, equals the sum of the opportunity cost in terms of foregone wage earnings and the opportunity cost in terms of foregone consumption, that is, $\left(\varepsilon_{t+1}+\theta\right) n_{t+1} y_{t+1}$. Thus, as is standard in the literature (Barro and Becker, 1989; Galor and Weil, 2000; Azarnert, 2008), these costs create a trade-off between the quality and quantity of children. This cost, however, is not with respect to education, but with respect to health.

\footnotetext{
${ }^{8}$ It may seem more appropriate to link the probability of survival to the total amount of in-kind aid received (i.e., $\left.A^{f}\right)$. Our results, however, do not depend on this assumption, which, as will become clear below, simplifies the comparison between the quantitative effects of the two types of aid.
} 
Including the consumption of children in their parents' consumption, lifetime utility at the beginning of period $t+1$ of a (surviving) agent born at $\mathrm{t}$ is specified as follows:

$$
U_{t+1}=\ln \left(c_{t+1}^{t}\right)+\eta_{L} \ln \left[1-p_{t+1}(f) n_{t+1} \varepsilon_{t+1}\right]+\eta_{N} \ln \left[p_{t+1}(f) n_{t+1} h_{t+1}^{C}\right]
$$

where $U_{t+j}$ and $c_{t+j}^{i}$ denote the utility and consumption of generation $i$ individuals at date $t+j$ and ln equals the natural logarithm operator. The term $\left[1-p_{t+1}(f) n_{t+1} \varepsilon_{t+1}\right]$ measures leisure in adulthood, whereas coefficients $\eta_{L}$ and $\eta_{N}$ measure the individual's relative preference for leisure and surviving healthy children. The term $\left[p_{t+1}(f) n_{t+1} h_{t+1}^{C}\right]$ equals actual family size [ $p_{t+1}(f) n_{t+1}$ ], which differs from fertility, $n_{\mathrm{t}+1}$, since the child survival rate is less than one, multiplied by the health status of a child, $h_{t+1}^{C}$. In the standard literature, parents derive utility from the 'raw' production of offspring. Here, however, the expected number of healthy children matters.

Assuming that child mortality occurs only at the beginning of the period, parents incur no childrearing costs for children who die. ${ }^{9}$ Because no consumption in childhood exists, the period-specific budget constraint is as follows:

$$
c_{t+1}^{t}=\left[1-\theta p_{t+1}(f) n_{t+1}\right] \alpha_{t+1} w_{t+1}+A^{c} n_{t+1} .
$$

\section{Firms}

We assume a simple technology where aggregate output is given by

$$
Y_{t}=B_{t} N_{t},
$$

\footnotetext{
${ }^{9}$ Alternatively, we could assume that parents incur childrearing costs for all children, regardless of whether they survive or not. The assumption in the text seems more natural, given that in many poor countries mortality in childhood tends to occur early in the life of children.
} 
where $B_{t}$ denotes each firm's common, average, economy-wide labor productivity and $N_{t}$ denotes the number of adult workers employed. Thus, production exhibits constant returns to scale in effective labor $B_{t} N_{t}$, which gives rise to endogenous growth in the steady state.

Health status and productivity

Following Agénor (2009) and Neanidis (2012), the health status of a child, $h_{t}^{C}$, depends on goods purchased out of parents' income, the parent's health status, $h_{t}^{A}$, and the time allocated by their parent to rearing them:

$$
h_{t}^{C}=\theta\left(h_{t}^{A}\right)\left(\varepsilon_{t}\right)^{v},
$$

where $v \in(0,1)$ is an efficiency parameter. First, a child's health status is linear in the share of resources spent by the parent, $\theta$, because it improves a child's health and nutrition, thereby reducing the child's vulnerability to disease (Pelletier et al., 2003; Caulfield et al., 2004). Second, a child's health depends on the parent's health, which may relate to the effect of parents' mental distress and anxiety on children's life satisfaction (Larson and Gillman, 1999; Downey et al., 1999) and their physical ability to take care of their children. It may also reflect Barker's (1998) 'foetal origins hypothesis', which suggests that conditions in utero may exert long-lasting effects on an individual's health (see, for evidence, Almond, 2006 and the survey by Almond and Currie, 2011). Third, the health status of a child depends on the time allocated to the child by the parent.

To capture the idea, established by recent work, that events in early life can exert large long-term effects on adult outcomes, we assume that the health status of adults depends only on health status in childhood. Studies that support this link include Fogel (1994), Strauss and Thomas (1998), Case, et al. (2002), Smith (2009) and, more recently, the surveys by Behrman 
(2009), Currie (2009), and Bleakley (2010). As a result, health status displays persistence, as in de la Croix and Licandro (2007) and Osang and Sarkar (2008). Given this evidence, we specify

$$
h_{t+1}^{A}=h_{t}^{C} .
$$

Substituting (5) into (6) yields

$$
h_{t+1}^{A}=\theta\left(h_{t}^{A}\right)\left(\varepsilon_{t}\right)^{v} .
$$

Thus, because a parent's health affects the children's health, and because adult well-being depends on own health in childhood, serial dependence exists in $h_{t}^{A}$. This specification conforms to Grossman (1972), who views health as a durable stock, which increases here with more spending on goods but also with more time taking care of one's children.

In line with the empirical evidence, and the specification in Agénor (2009) and Neanidis (2012), we assume that adult productivity depends linearly on health status:

$$
\alpha_{t}=h_{t}^{A}
$$

\section{Long-run equilibrium, choice of time and fertility, and macroeconomic dynamics}

This section determines the long-run equilibrium outcomes for fertility, the time allocated to childrearing, economic growth, and welfare. Then, we explicitly determine the effects of in-kind and monetary humanitarian aid on these equilibrium outcomes.

Equilibrium solutions

The discussion begins with the definition of a competitive equilibrium:

Definition 1. A competitive equilibrium for this economy is a sequence of prices $\left\{w_{t}\right\}_{t=0}^{\infty}$,

allocations $\left\{c_{t+1}^{t}, \varepsilon_{t+1}\right\}_{t=0}^{\infty}$, and health status of children and adults $\left\{h_{t}^{C}, h_{t}^{A}\right\}_{t=0}^{\infty}$ such that, given the initial health statuses $h_{0}^{C}>0$ and $h_{0}^{A}>0$, individuals maximize utility, firms maximize profits, and markets clear. 
In equilibrium, individual productivity equals the economy-wide average productivity, so that $\alpha_{t}=B_{t}$. In addition, we simplify and assume that children of each generation face an identical probability of survival to adulthood. That is, $p_{t}(f)=p_{t+1}(f)=p(f)$. This assumption leads to the definition of the balanced growth path as follows:

Definition 2. A balanced growth equilibrium is a competitive equilibrium in which $c_{t}^{t}, c_{t+1}^{t}, h_{t}^{C}, h_{t}^{A}$ and $\left(Y_{t} / N_{t}\right)$, all grow at the constant rate $1+\gamma$.

Each adult maximizes equation (3) subject to equations (1), (4), (6), and (7), with respect to $c_{t+1}^{t}, \varepsilon_{t+1}$, and $n_{t+1}$, taking $c$ and $p(f)$ as given. The solution to the household problem follows closely the derivation in Appendix A of Neanidis (2012).

Remembering that $\alpha_{t}=B_{t}$ in equilibrium, solving the model yields the following solutions for fertility, child rearing time, and per capita growth respectively:

$$
\begin{aligned}
& \tilde{n}=\frac{\eta_{N}(1-v)}{[\theta p(f)-c]\left[1+\eta_{N}(1-v)\right]}, \\
& \tilde{\varepsilon}=\Lambda\left\{\frac{[\theta p(f)-c]\left[1+\eta_{N}(1-v)\right]}{p(f) \eta_{N}(1-v)}\right\}, \text { and } \\
& 1+\gamma=\theta\left\{\Lambda \frac{[\theta p(f)-c]\left[1+\eta_{N}(1-v)\right]}{p(f) \eta_{N}(1-v)}\right\}^{v},
\end{aligned}
$$

where $\Lambda \equiv \eta_{N} v /\left(\eta_{L}+\eta_{N} v\right) .{ }^{10}$ We impose the following two assumptions to ensure (i) positive values for the equilibrium solutions, and (ii) that the population size does not converge to zero $(p(f) \tilde{n} \geq 1)$, respectively. That is,

Assumption 1: $p(f)>\frac{c}{\theta}$; and

\footnotetext{
${ }^{10}$ We can easily show that $p(f) \tilde{n} \tilde{\varepsilon}=\Lambda<1$, which implies a feasible time allocation with positive leisure in equilibrium.
} 
Assumption 2: $\frac{\theta p(f)-c}{p(f)} \leq \frac{\eta_{N}(1-v)}{1+\eta_{N}(1-v)} \equiv \Gamma$

The first assumption requires that the fraction of income received as monetary aid is small compared to the fraction of income spent on caring for each child, while the second assumption requires that the latter amount is not too large either.

Equation (12) implies that the model exhibits no transitional dynamics. Following a shock, the time adults allocate to child rearing jumps immediately to its new equilibrium value, where it stays thereafter. In addition, the health status of both adults and children grow at the same constant rate.

Implications of changes in humanitarian aid for fertility, time allocation, and growth

Equations (10), (11), and (12) determine the steady state fertility rate, time allocation to child rearing, and growth rate, respectively. We now consider the effects of changes in humanitarian aid on the steady-state equilibrium. More specifically, we consider the effect of changes in inkind and monetary humanitarian aid on the fertility rate, the time allocation to child rearing, and the growth rate. An increase in in-kind aid means an increase in $f$, while an increase in monetary aid means an increase in $c$, which correspond to the exogenous components of these types of aid (see equations (1) and (2)). Thus, from equations (10) and (11), we can derive the following outcomes, used to establish Proposition 1:

$$
\begin{aligned}
& \frac{d \tilde{n}}{d f}=-\frac{\Gamma \theta p^{\prime}(f)}{[\theta p(f)-c]^{2}}<0 ; \quad \frac{d \tilde{n}}{d c}=\frac{\Gamma}{[\theta p(f)-c]^{2}}>0, \\
& \frac{d \tilde{\varepsilon}}{d f}=\frac{p^{\prime}(f) c \Lambda}{[p(f)]^{2} \Gamma}>0 ; \quad \frac{d \tilde{\varepsilon}}{d c}=-\frac{\Lambda}{p(f) \Gamma}<0 .
\end{aligned}
$$

Proposition 1. An increase in humanitarian aid in the form of in-kind (monetary) aid reduces (increases) fertility and increases (reduces) parents’ childrearing time for each child. 
In-kind aid exerts a negative effect on fertility by increasing the probability of survival from childhood to adulthood. The fact that the fertility rate inversely relates to the survival probability conforms to Kalemli-Ozcan (2003), who explicitly considers in a stochastic framework ex ante uncertainty about the number of surviving children. Higher mortality increases the number of births beyond the number required to produce the desired and expected number of survivors. As mortality rates, and thus uncertainty, fall, the precautionary demand for children also decreases. Jeon et al. (2008) and Neanidis (2012) provide evidence that supports this view. That is, they show that a decline in infant mortality (a proxy for higher child survival rate) decreases the fertility rate. Monetary aid, on the other hand, increases fertility by reducing the 'quantity cost' of children, thereby shifting resources from children's quality to their quantity. Therefore, as Azarnert (2008) also finds, monetary aid increases the return on child quantity. Neanidis (2012) offers empirical support for this positive effect for those countries that did not undergo demographic transition (i.e., high-fertility-rate countries).

The effect of humanitarian aid on parents' childrearing time also works in conflicting directions. In-kind aid exerts a positive effect on the time allocated to childrearing for each child as a consequence of the lower number of children. Thus, parents spend more time on each of their children. Monetary aid proportional to the number of born children, on the other hand, induces parents to decrease their childrearing time for each child as their expected (monetary) gain for each born child rises.

From equation (12), we can derive the following effect of humanitarian aid on long-run growth, which is summarized in Proposition 2:

$$
\frac{d(1+\gamma)}{d f}=\frac{(1+\gamma) v}{[\theta p(f)-c]} \frac{p^{\prime}(f) c}{p(f)}>0 ; \quad \frac{d(1+\gamma)}{d c}=-\frac{(1+\gamma) v}{[\theta p(f)-c]}<0 .
$$


Proposition 2. An increase in humanitarian aid in the form of in-kind (monetary) aid exerts a positive (negative) effect on growth.

The increase in humanitarian aid produces an unclear effect on the economic growth rate because of the opposing effects of in-kind and monetary aid per child. In-kind aid exerts a positive effect on growth by directly enhancing the health status of surviving children and their productivity during adulthood. Monetary aid per child, on the other hand, reduces the childrearing time that adults allocate to their children, which lowers children's health status. This, in turn, reduces health status in adulthood, and subsequently the rate of economic growth. The positive effect of in-kind aid on economic growth finds empirical support in Bezuneh, et al. (2003) for the case of Tunisia, while the negative effect of monetary aid finds empirical support by Neanidis (2012) for sub-Saharan Africa.

These findings demonstrate the ambiguity of the effects of total humanitarian aid. We, however, can derive the conditions under which the effects of one type of humanitarian aid dominate the other. Since the effects of in-kind and monetary aid exhibit opposite signs, we take the absolute value of the ratios of the partial derivatives with respect to in-kind and monetary aid, described in equations (13) through (15). The following expressions result:

$$
\begin{aligned}
& \left|\frac{\frac{d \tilde{n}}{d f}}{\frac{d \tilde{n}}{d c}}\right|=\theta p^{\prime}(f) \text {, and } \\
& \left|\frac{\frac{d \tilde{\varepsilon}}{d f}}{\frac{d \tilde{\varepsilon}}{d c}}\right|=\left|\frac{\frac{d(1+\gamma)}{d f}}{\frac{d(1+\gamma)}{d c}}\right|=\frac{p^{\prime}(f) c}{p(f)} .
\end{aligned}
$$

Equation (16) implies that, in absolute magnitude, the effect of in-kind aid on equilibrium fertility dominates that of monetary aid, when the marginal effect of in-kind aid on the 
probability of survival to adulthood is sufficiently large, $p^{\prime}(f)>1 / \theta$. Otherwise, monetary aid exhibits a quantitatively greater effect on steady-state fertility.

Equation (17) leads to the following result:

$$
\left|\frac{\frac{d \tilde{\varepsilon}}{d f}}{\frac{d \tilde{\varepsilon}}{d c}}\right|=\left|\frac{\frac{d(1+\gamma)}{d f}}{\frac{d(1+\gamma)}{d c}}\right|\left\{\begin{array}{l}
> \\
= \\
<
\end{array}\right\} \text { iff } \frac{p^{\prime}(f) f}{p(f)}\left\{\begin{array}{l}
> \\
=\} \\
<
\end{array}\right\} \frac{f}{c}=\frac{A^{f}}{A^{c}},
$$

remembering that in-kind and monetary aid are proportional to recipient's labor income (see equations (1) and (2)). Further, Assumption 1 implies the following relationship between equations (16) and (17):

$$
\left|\frac{\frac{d \tilde{\varepsilon}}{d f}}{\frac{d \tilde{\varepsilon}}{d c}}\right|=\left|\frac{\frac{d(1+\gamma)}{d f}}{\frac{d(1+\gamma)}{d c}}\right|<\left|\frac{\frac{d \tilde{n}}{d f}}{\frac{d \tilde{n}}{d c}}\right| .
$$

Intuitively, condition (18) suggests that the magnitude of the effect of in-kind aid on parent's childrearing time and economic growth exceeds (falls below) the effect of monetary aid when the elasticity of the probability of a child's survival into adulthood with respect to in-kind aid exceeds (falls below) the ratio of in-kind aid to monetary aid. This implies that an aid distribution between in-kind and monetary forms can achieve a desired increase in economic growth as long as the elasticity of a child's survival likelihood with respect to in-kind aid is sufficiently high. For instance, if the proportion of total aid given in the form of in-kind is low compared to its monetary counterpart (i.e., a small $A^{f} / A^{c}$ ), as long as the survival probability greatly responds to the rise in in-kind aid, then the overall growth effect of humanitarian aid is positive. If, on the other hand, the responsiveness is low, even a much higher size of in-kind aid compared to money aid will not be sufficient to preclude a decline in economic growth. 
The above, then, imply that policy makers can design aid distribution programs to increase economic growth by comparing the allocation of aid into its in-kind and monetary types to how responsive the children's survival rate is to in-kind aid. As long as this responsiveness is high, even a small amount of in-kind aid can put the recipient on a path of higher economic growth.

Implications of changes in humanitarian aid for welfare

Microeconomic theory generally argues that money transfers leave individuals better off than targeted, in-kind transfers, since individuals allocate the money to their best use (e.g., Currie and Gahvari, 2008). This means that monetary (cash) aid should leave individuals better off in terms of welfare when compared to in-kind aid, as cash aid does not constrain the behavior of the recipients. In practice, however, in-kind aid programs are widespread and sizeable across the world (see Currie and Gahvari, 2008; Tables 1-3). This contradiction between traditional theory and actual data generated a literature that offers competing explanations for the dominance of inkind transfers. A popular explanation, paternalism, involves the conflict between donor and recipient preferences. Since recipients do not calculate the social benefits while donors do, the social benefits from the provision of certain goods and services can provide the rationale for using in-kind aid.

In our model, parents may not fully incorporate their children's satisfaction or the social benefits implied by investment in their health. That is, underinvestment in the health of children leads to poorer less healthy lives in adulthood, on average, and at the same time, lowers economic growth, because of reduced health status and productivity. Currie and Gahvari (2008) conclude in their survey of the theory and data on cash and in-kind aid that paternalism with 
interdependent preferences provides the best overall explanation of the dominance of in-kind aid in practice. ${ }^{11}$

Our model offers an alternative explanation for which of the two types of aid dominates in terms of the recipient's utility. The outcome depends on a condition that incorporates the weight parents attach to the number of surviving healthy children in their utility $\left(\eta_{N}\right)$ and the health-related efficiency of the time allocated to rearing their children $(v)$. Thus, under certain conditions, welfare produced with targeted, in-kind transfers by aid distributors can exceed the welfare garnered by money aid.

The analysis is as follows. Substitute equations (1), (4), and (9) into the utility function, equation (3), to get

$$
\begin{aligned}
U_{t+1}=\ln \{[1 & \left.\left.-\theta p_{t+1}(f) n_{t+1}+c n_{t+1}\right] h_{t+1}^{A} w_{t+1}\right\} \\
& +\eta_{L} \ln \left[1-p_{t+1}(f) n_{t+1} \varepsilon_{t+1}\right]+\eta_{N} \ln \left[p_{t+1}(f) n_{t+1} h_{t+1}^{C}\right] .
\end{aligned}
$$

Using equation (7), and expanding parts of the terms in natural logarithms, we see that

$$
\begin{aligned}
U_{t+1}=\ln \left\{\left[1-\theta p_{t+1}(f) n_{t+1}+c n_{t+1}\right] w_{t+1}\right\}+\ln h_{t+1}^{A} \\
\quad+\eta_{L} \ln \left[1-p_{t+1}(f) n_{t+1} \varepsilon_{t+1}\right]+\eta_{N} \ln \left[p_{t+1}(f) n_{t+1}\right]+\eta_{N} \ln h_{t+2}^{A} .
\end{aligned}
$$

Combining equations (6) and (12) leads to the following backward induction:

$$
\ln h_{t+1}^{A}+\eta_{N} \ln h_{t+2}^{A}=\ln \left[\left(h_{0}^{A}\right)^{1+\eta_{N}}(1+\gamma)^{(t+1)\left(1+\eta_{N}\right)+\eta_{N}}\right]
$$

where, as noted earlier, $h_{0}^{A}>0$ is the initial adult health status. Substituting equation (22) into equation (21), along with the assumption that $p_{t}(f)=p_{t+1}(f)=p(f)$, and the result that in the steady-state equilibrium, $w_{t+1}=1, n_{t+1}=\tilde{n}$, and $\varepsilon_{t+1}=\widetilde{\varepsilon}$, leads to the following relationship

\footnotetext{
${ }^{11}$ See Daly and Giertz (1972), Garfinkle (1973), and Olsen (1980) for earlier studies of paternalism with interdependent preferences.
} 


$$
\begin{aligned}
\tilde{U}=\ln & \left\{1-\left[\theta p\left(A^{f}\right)-c\right] \tilde{n}\right\}+\eta_{L} \ln [1-p(f) \tilde{n} \tilde{\varepsilon}] \\
& +\eta_{N} \ln [p(f) \tilde{n}]+\ln \left(h_{0}^{A}\right)^{1+\eta_{N}}+\left[(t+1)\left(1+\eta_{N}\right)+\eta_{N}\right] \ln (1+\gamma) .
\end{aligned}
$$

Now, substitute into equation (23) the steady-state values for the fertility rate and the time spent childrearing from equations (10) and (11), respectively, to get

$$
\begin{aligned}
\tilde{U}=\ln & \left\{1-\frac{\eta_{N}(1-v)}{1+\eta_{N}(1-v)}\right\}+\eta_{L} \ln (1-\Lambda) \\
& +\eta_{N} \ln \left\{\frac{p(f) \eta_{N}(1-v)}{[\theta p(f)-c]\left[1+\eta_{N}(1-v)\right]}\right\} \\
& +\ln \left(h_{0}^{A}\right)^{1+\eta_{N}}+\left[(t+1)\left(1+\eta_{N}\right)+\eta_{N}\right] \ln (1+\gamma) .
\end{aligned}
$$

Remembering that $\Lambda \equiv \eta_{N} v /\left(\eta_{L}+\eta_{N} v\right)$, and simplifying equation (24), leads to

$$
\begin{aligned}
\tilde{U}=\ln & \left(\frac{1}{1+\eta_{N}(1-v)}\right)+\eta_{L} \ln \left(\frac{\eta_{L}}{\eta_{L}+\eta_{N} v}\right) \\
& +\eta_{N} \ln \left\{\frac{p(f) \eta_{N}(1-v)}{[\theta p(f)-c]\left[1+\eta_{N}(1-v)\right]}\right\} \\
& +\ln \left(h_{0}^{A}\right)^{1+\eta_{N}}+\left[(t+1)\left(1+\eta_{N}\right)+\eta_{N}\right] \ln (1+\gamma) .
\end{aligned}
$$

Differentiation of equation (25) with respect to $f$ and $c$ gives rise to the welfare effects of in-kind and monetary aid, respectively. The effects of aid emerge from the third and fifth terms on the right-hand side of equation (25), as the remaining terms are constant. The following result holds, summarized in Proposition 3:

$$
\begin{aligned}
& \frac{d \tilde{U}}{d f}=\frac{p^{\prime}(f) c}{p(f)[\theta p(f)-c]}\left\{\left[(t+1)\left(1+\eta_{N}\right)+\eta_{N}\right] v-\eta_{N}\right\} \text {, and } \\
& \frac{d \tilde{U}}{d c}=-\frac{1}{[\theta p(f)-c]}\left\{\left[(t+1)\left(1+\eta_{N}\right)+\eta_{N}\right] v-\eta_{N}\right\} .
\end{aligned}
$$

Proposition 3. An increase in humanitarian aid of either form, in-kind or monetary, exerts an ambiguous effect on welfare. 
Either type of aid may increase or decrease welfare. In-kind aid transfers decrease the number of children (family size) as aid increases the likelihood of survival to adulthood. Given that parents value children, however, a decline in their numbers diminishes welfare. At the same time, in-kind aid enhances growth by raising the amount of time parents allocate to their children. As higher growth exerts a positive effect on welfare (see equation (25)), so does in-kind aid. Monetary-per-child aid, on the other hand, produces exactly the opposite effects. Monetary aid raises the optimal number of children, as parents prefer the quantity of children rather than their quality, thus, raising welfare. But through the negative effect monetary aid exerts on growth, by decreasing the time parents allocate to offspring, it diminishes welfare.

Equations (26) and (27) illustrate that a single condition determines which of the two offsetting effects, of both types of aid, dominates the other. This is shown as follows:

$$
\begin{aligned}
& \frac{d \tilde{U}}{d f}>0 \text { and } \frac{d \tilde{U}}{d c}<0 \text {, if }(t+1)\left(1+\eta_{N}\right) v>\eta_{N}(1-v) \\
& \frac{d \tilde{U}}{d f}<0 \text { and } \frac{d \tilde{U}}{d c}>0 \text {, if }(t+1)\left(1+\eta_{N}\right) v<\eta_{N}(1-v)
\end{aligned}
$$

Intuitively, we can rewrite this condition in terms of how much individuals value the number of surviving healthy children $\left(\eta_{N}\right)$ or in terms of the elasticity of health status with respect to the time individuals allocate to rearing their children $(v)$. If $\eta_{N}$ is relatively low, or $v$ relatively high, in-kind aid exerts a positive welfare effect while monetary aid exerts a negative welfare effect. In contrast, if $\eta_{N}$ is relatively high, or $v$ relatively low, in-kind aid exerts a negative welfare effect while monetary aid exerts a positive welfare effect. The threshold values of $\eta_{N}$, or $v$, are:

$$
\eta_{\mathrm{N}}=\frac{(t+1) v}{1-(t+2) v}
$$




$$
v=\frac{\eta_{N}}{\eta_{N}+(t+1)\left(1+\eta_{N}\right)}
$$

The interpretation is as follows. If individuals strongly value the quantity of children, giving monetary aid for every child induces more children. The welfare effect of money aid is positive even if an indirect negative welfare effect takes place through lower growth rates. But, if individuals value the quality of their children (health status), they will obtain greater utility by inkind aid. Based on these results, aid donors could raise the recipient's welfare by designing an aid distribution program that considers parents’ preferences toward the number of children. ${ }^{12}$

Finally, the relative magnitude of the welfare effects of in-kind and monetary aid is determined as follows:

$$
\left|\frac{\frac{d \tilde{U}}{d f}}{\frac{d \tilde{U}}{d c}}\right|=\frac{p^{\prime}(f) c}{p(f)},
$$

which implies

$$
\left|\frac{\frac{d \tilde{U}}{d f}}{\frac{d \tilde{U}}{d c}}\right|\left\{\begin{array}{l}
> \\
= \\
<
\end{array}\right\} \text { iiff } \frac{p^{\prime}(f) f}{p(f)}\left\{\begin{array}{l}
> \\
= \\
<
\end{array}\right\} \frac{f}{c}=\frac{A^{f}}{A^{c}} .
$$

This condition appeared in equation (18) when we described the effects of in-kind and monetary aid on time spent in childrearing and on economic growth. The interpretation is similar here. The magnitude of the effect of in-kind aid on equilibrium welfare exceeds (falls below) the effect of monetary aid when the elasticity of the probability of a child's survival into adulthood with

\footnotetext{
${ }^{12}$ One may also consider the situation where donors exhibit different preferences than recipients with regard to the number of children. In this case, the recipient country policy makers could undertake policies to alter the preferences of their population to match those of the donors. This would correspond to the case of interdependent preferences between recipients and donors advanced by Daly and Giertz (1972) and Garfinkel (1973). This issue, however, lies outside the focus of this study, where preferences are viewed as given.
} 
respect to in-kind aid exceeds (falls below) the ratio of in-kind to monetary aid. In other words, in-kind aid can enhance welfare as long as the children's survival rate responds sufficiently to this type of aid. This result illustrates that our model offers another explanation for the potential dominance of in-kind aid compared to monetary transfers, as reflected in the actual aid data, beyond paternalism and interdependent preferences between donor and recipient.

\section{Concluding remarks}

This paper examines how humanitarian aid may affect demographic transition and economic welfare. It extends the work in Neanidis (2012), which focuses on economic growth. The analysis in this paper illustrates the complexity of the channels and the ambiguity of the effects of humanitarian aid.

Our study utilizes a two-period OLG model with endogenous fertility, where agents live (at most) for two periods: childhood and adulthood. As agents, parents decide how to allocate their time between leisure and childrearing activities, with the latter improving the health status of children. This, in turn, enhances future adult labor productivity. Humanitarian aid is given in two forms: in-kind and monetary. Both types of aid improve children health status. In-kind aid increases a child's likelihood of survival to adulthood, while monetary aid directly contributes to parent's income to finance spending on children's health. In this environment, we assess the effect of humanitarian aid by examining independently each of its two forms.

The analysis arrives at the following conclusions. In-kind aid leads to more time allocated to childrearing and higher economic growth, as well as lower fertility. At the same time, it leads to higher welfare only if parents place a low relative weight on the number of children. In the opposite case, welfare diminishes. The effects of monetary aid go in the opposite direction. Higher money aid raises fertility while it lowers childrearing time and economic growth. The 
influence on welfare depends, once again, on parent's attitude toward child quantity. If parents prefer more children, monetary aid leads to higher welfare. In the opposite case, welfare diminishes.

In terms of aid distribution programs, our results have two important qualifications. First, since humanitarian aid affects fertility, growth and welfare, policy makers can use this type of aid for policy considerations. This is in addition to, what is called productive aid, the effects of which have dominated the aid literature. Second, the allocation of humanitarian aid between its two forms, in-kind and monetary, plays a crucial role in the way it feeds through the economy. This distinction can assist aid donors and recipient governments to design aid schemes to achieve their objectives.

According to our results, if the main objective is to achieve demographic transition and raise economic growth, then a humanitarian aid program should include in-kind aid, as long as the elasticity of the children's survival probability with respect to in-kind aid exceeds the ratio of in-kind to monetary aid. If the aim is to increase welfare, however, then the aid program must consider the population's preferences toward children quantity (or quality) as both types of aid can generate higher welfare. Specifically, policy makers can achieve both higher economic growth and welfare with in-kind aid, as long as recipients attach a relatively low value on the number of children.

As stated earlier, microeconomic theory generally argues that money transfers leave individuals better off than targeted, in-kind transfers. In our model, in-kind aid can also lead to higher growth and social welfare. Thus, our model offers another explanation for the importance of in-kind aid. Overall, the analysis shows that allocation of aid transfers tied to certain activities (in-kind) can produce both positive growth and welfare effects. In this way, aid distributors can 
assist countries in achieving both improved economic growth and welfare by targeting the types of aid allocated. 


\section{References}

Agénor, P-R., (2009). Public capital, health persistence, and poverty traps. Working Paper no. 115, Centre for Growth and Business Cycle Research, University of Manchester.

Agénor, P-R., and Yilmaz, D., (2012). Aid allocation, growth and welfare with productive public goods. International Journal of Finance and Economics, forthcoming.

Almond, D., (2006). Is the 1918 influenza pandemic over? Long-term effects of in utero influenza exposure in the post-1940 U.S. population. Journal of Political Economy 114, $672-712$.

Almond, D., and Currie, J., (2011). Human capital development before age five. Handbook of Labor Economics 4B, Chapter 15, 1315-1486.

Angeles, L., and Neanidis, K. C., (2009). Aid effectiveness: the role of the local elite. Journal of Development Economics 90, 120-134.

Azarnert, L. V., 2008. Foreign aid, fertility and human capital accumulation. Economica 75, 766-81.

Barker, D. J. P., (1998). Mothers, Babies and Health in Later Life. 2nd ed. Edinburgh: Churchill Livingston.

Barro, R. J., and Becker, G. S., (1989). Fertility choice in a model of economic growth. Econometrica 57, 481-501.

Becker, G. S., (1960). An economic analysis of fertility. In NBER, Demographic and Economic Change in Developed Countries, National Bureau Conference Series no. 10. Princeton, NJ: Princeton University Press.

Becker, G. S., (2007). Health as human capital: synthesis and extensions. Oxford Economic Papers 59, 379-410.

Behrman, J. R., (2009). Early life nutrition and subsequent education, health, wage, and intergenerational effects. In Health and Growth, ed. by Michael Spence and Maureen Lewis, Washington DC: World Bank.

Bhagwati, J.N., (1958). Immiserizing growth: a geometrical note. Review of Economic Studies 25, 201-205.

Bhagwati, J.N., Brecher, R., and Hatta, T., (1985). The generalized theory of transfers and welfare: exogenous (policy-imposed) and endogenous (transfer-induced) distortions. Quarterly Journal of Economics 160(3), 697-714. 
Bleakley, H., (2010). Malaria eradication in the Americas: a retrospective analysis of childhood exposure. American Economic Journal: Applied Economics 2, 1-45.

Case, A., Fertig, A., and Paxson, C., (2005). The lasting impact of childhood health and circumstance. Journal of Health Economics 24, 365-89.

Case, A., Lubotsky, D., and Paxson, C., (2002). Economic status and health in childhood: the origins of the gradient. American Economic Review 92, 1308-1334.

Caulfield, L. E., De Onis, M., Bloessner, M., and Black, R. E., (2004). Undernutrition as an underlying cause of child deaths associated with diarrhea, pneumonia, malaria, and measles. American Journal of Clinical Nutrition 80, 193-198.

Center for Global Development, (2007). Millions saved: proven successes in global health. Center for Global Development, Washington, DC.

Chakraborty, S., (2004). Endogenous lifetime and economic growth. Journal of Economic Theory 116, 119-37.

Chatterjee, S., Sakoulis, G., and Turnovsky S.J., (2003). Unilateral capital transfers, public investment, and economic growth. European Economic Review 47, 1077-1103.

Chatterjee, S., and Turnovsky, S.J., (2005). Financing public investment through foreign aid: consequences for economic growth and welfare. Review of International Economics 13, 20-44.

Clemens, M. A., Radelet, S., and Bhavnani, R., (2004). Counting chickens when they hatch: The short-term effect of aid on growth. . Working Paper, vol. 44. Center for Global Development.

Collier, P., and Hoeffler, A., (2004). Aid, policy and growth in post-conflict societies. European Economic Review 48, 1125-1145.

Currie, J., (2009). Healthy, wealthy, and wise: Socioeconomic status, poor health in childhood, and human capital development. Journal of Economic Literature 47, 87-122.

Currie, J., and Gahvari, F., 2008. Transfers in cash and in-kind: Theory meets the data. Journal of Economic Literature 46, 333-383.

Daalgard, C-J., (2008). Donor policy rules and aid effectiveness. Journal of Economic Dynamics \& Control 32, 1895-1920.

Daalgard, C-J., and Hansen, H., (2010). Evaluating aid effectiveness in the aggregate: A critical assessment of the evidence. MPRA Working Paper \#23026. 
Daalgard, C-J., Hansen, H., and Tarp, F., (2004). On the empirics of foreign aid and growth. Economic Journal 114, F191-F216.

Daly, G., and Giertz, F., 1972. Welfare economics and welfare reform. American Economic Review 62, 131-138.

De la Croix, D., and Licandro, O., (2007). 'The child is the father of the man:' implications for the demographic transition. Unpublished, Université Catholique de Louvain.

De Waal, A., Taffesse, S., and Carruth, L., (2006). Child survival during the 2002-2003 drought in Ethiopia. Global Public Health 1(2), 125-32.

Djajić, S., (2009). Foreign aid, infrastructure development and welfare: an intertemporal analysis. Review of Development Economics 13(3), 393-402.

Djajić, S., Lahiri, S., and Raimondos-Møller, P., (1999). Foreign aid, domestic investment and welfare. Economic Journal 109, 698-707.

Downey, G., Purdie, V., and Schaffer-Neitz, R., (1999). Anger transmission from mother to child: a comparison of mothers in chronic pain and well mothers. Journal of Marriage and the Family 61, 62-73.

Fogel, R. W., (1994). Economic growth, population theory, and physiology: The bearing of longterm economic processes on the making of economic policy. American Economic Review 84, 369-395.

Galor, O., and Weil, D. N., (2000). Population, technology, and growth: from the Malthusian regime to the demographic transition and beyond. American Economic Review 90, 80628.

Garfinkel, I., 1973. Is in-kind redistribution efficient? Quarterly Journal of Economics 87, 320330.

Grossman, M., (1972). On the concept of health capital and the demand for health. Journal of Political Economy 80, 223-255.

Hatzipanayotou, P., and Michael, M. S., (2000). The financing of foreign aid and welfare: income versus consumption tax. Review of Development Economics 4, 21-38.

Huff, H. B., and Jimenez, M., (2003). The food aid convention: past performance and future role within the new global trade and development environment. Paper presented at the International Conference on Agricultural Policy Reform and the WTO: Where are we Heading? Capri, Italy.

Jeon, Y., Rhyu, S-Y., and Shields, M. P., (2008). Fertility in sub-Saharan African countries with consideration to health and poverty. Discussion Paper no. 3526, IZA. 
Kalemli-Ozcan, S., (2003). A stochastic model of mortality, fertility, and human capital investment. Journal of Development Economics 70, 103-18.

Lahiri, S., Raimondos-Møller, P., Wong, K.-Y., and Woodland, A., (2002). Optimal foreign aid and tariffs. Journal of Development Economics 67, 79-99.

Lahiri, S., and Raimondos-Møller, R., (1995). Welfare effects of aid under quantitative trade restrictions. Journal of International Economics 39, 297-315.

Larson, R. W., and Gillman, S., (1999). Transmission of emotions in the daily interactions of single-mother families. Journal of Marriage and the Family 61, 21-37.

Minoiu, C., and Reddy, S. G., (2010). Development aid and growth: a positive long-run relation. Quarterly Review of Economics and Finance 50(1), 27-39.

Neanidis, K., (2012). Humanitarian aid, fertility and economic growth. Economica, 79, 27-61.

Neanidis, K. C., and Varvarigos, D., (2009). The allocation of volatile aid and economic growth: theory and evidence. European Journal of Political Economy 25(4), 447-62.

Olsen, E. O., 1980. Pareto-desirable redistribution in kind: Comment." American Economic Review 70, 1028-1031.

Osang, T., and Sarkar, J., (2008). Endogenous mortality, human capital and endogenous growth. Journal of Macroeconomics 30, 1423-1445.

Pelletier, D. L., Frongillo, E. A., and Habicht, J-P., (2003). Epidemiologic evidence for a potentiating effect of malnutrition on child mortality. American Journal of Public Health 83, 1130-1133.

Plumber, T., and Neumayer, E., (2009). Famine mortality, rational political inactivity, and international food aid. World Development 37(1), 50-61.

Powdthavee, N., and Vignoles, A., (2008). Mental health of parents and life satisfaction of children: a within family analysis of intergenerational transmission of well-being. Discussion Paper no. 20, University of York.

Shimomura, K., (2007). A Pareto-improving foreign aid in a dynamic North-South model. Theory and Practice of Foreign Aid, 1(1), 131-153.

Smith, J. P., (2009). The impact of childhood health on adult labor market outcomes. Review of Economics and Statistics 91, 478-489.

Strauss, J., and Thomas, D., (1998). Health, nutrition and economic development. Journal of Economic Literature 36, 766-817. 